\title{
Revealing Hydrogenation Reaction Pathways on Naked Gold Nanoparticles
}

\author{
Leandro Luza, $^{\dagger}$ Camila P. Rambor, $^{\dagger}$ Aitor Gual, ${ }^{\ddagger}$ Jesum Alves Fernandes, ${ }^{\ddagger}$ Dario Eberhardt, ${ }^{\S}$ \\ and Jairton Dupont $*, \dagger, \ddagger$ \\ ${ }^{\dagger}$ Institute of Chemistry, Universidade Federal do Rio Grande do Sul, Av. Bento Gonçalves, 9500 Porto Alegre, Brazil \\ ¥GSK Carbon Neutral Laboratory for Sustainable Chemistry, University of Nottingham, NG7 2TU Nottingham, U.K. \\ ${ }^{\S}$ Physics Faculty, Pontifícia Universidade Católica do Rio Grande do Sul, Av. Ipiranga, 6681 Porto Alegre, Brazil
}

\author{
Supporting Information
}

\begin{abstract}
Gold nanoparticles (AuNPs) display distinct characteristics as hydrogenation catalysts, with higher selectivity and lower catalytic activity than group 8-10 metals. The ability of AuNPs to chemisorb/activate simple molecules is limited by the low coordination number of the surface sites. Understanding the distinct pathways involved in the hydrogenation reactions promoted by supported AuNPs is crucial for broadening their potential catalytic applications. In this study, we demonstrate that the mechanism of the hydrogenation reactions catalyzed by AuNPs with "clean" surfaces may proceed via homolytic or heterolytic hydrogen activation depending on the nature of the support. The synthesis of naked AuNPs employing $\gamma-\mathrm{Al}_{2} \mathrm{O}_{3}$ and ionic liquid (IL)-hybrid $\gamma-\mathrm{Al}_{2} \mathrm{O}_{3}$ supports was accomplished by sputtering deposition using ultrapure gold foils. This highly reproducible and straightforward procedure furnishes small $(\sim 6.6 \mathrm{~nm})$ and well-distributed

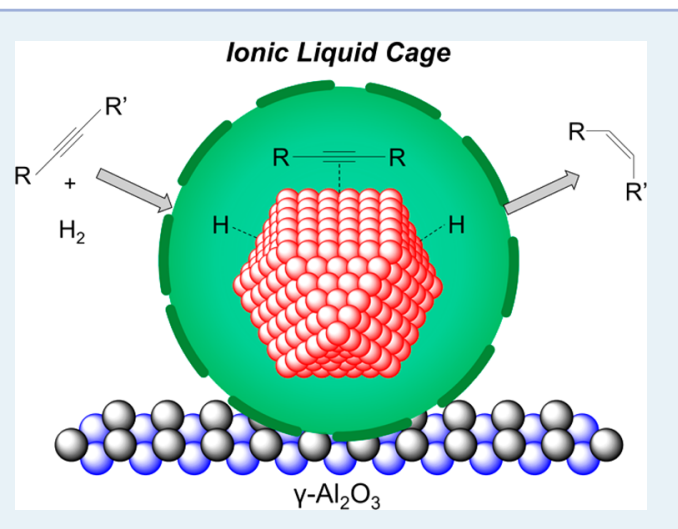
metallic gold nanoparticles $(\mathrm{Au}(0) \mathrm{NPs})$ that are found to be active catalysts for the partial and selective hydrogenation of substituted conjugated dienes, alkynes, and $\alpha, \beta$-unsaturated carbonyl compounds (aldehydes and ketones). Kinetic and deuterium labeling studies indicate that heterolytic hydrogen activation is the primary pathway occurring on the AuNPs imprinted directly on $\gamma-\mathrm{Al}_{2} \mathrm{O}_{3}$. In contrast, AuNPs supported on IL-hybrid $\gamma$ - $\mathrm{Al}_{2} \mathrm{O}_{3}$ materials cause the reaction to proceed via a homolytic hydrogen activation pathway. The IL layer surrounds the AuNPs and acts as a cage, influencing the frequency of the interaction of the catalytically active species and the metal surface and, consequently, the catalytic performance of the AuNPs. The IL layer is shown to improve the product selectivity by the enhancement of the substrate/product discrimination, and to decrease the catalytic activity by shifting the rate-determining step to the $\mathrm{H}_{2}$ and substrate competitive adsorption/activation on the same active sites. A series of kinetic experiments suggest that AuNPs imprinted on an IL-hybrid $\gamma-\mathrm{Al}_{2} \mathrm{O}_{3}$ support are more efficient (lower activation energy, $E_{\mathrm{a}}$ ) than group 8-10 metal based catalysts for hydrogenation reactions at moderate to high temperatures $\left(75-150{ }^{\circ} \mathrm{C}\right)$.
\end{abstract}

KEYWORDS: gold nanoparticles, supported ionic liquid, hydrogenation, disproportionation, sputtering

\section{INTRODUCTION}

Understanding the relationship between the electronic and structural properties of supported metal nanoparticles (MNPs) and their catalytic performance is one of the biggest challenges for their application in organic transformations on an industrial scale. $^{1-3}$ Gold nanoparticles (AuNPs) exhibit unique and distinct catalytic activity and selectivity in comparison to group 8-10 MNPs (see section S1 in the Supporting Information). ${ }^{4-6}$ Despite their relatively low catalytic activity, AuNPs are some of the most selective catalysts for the partial hydrogenation of, for example, alkynes and $\alpha, \beta$-unsaturated carbonyl substrates. ${ }^{5}$ It is assumed that their poor catalytic activity for hydrogenation reactions is mainly caused by the low frequency factor of hydrides (catalytically active species) on the metal surface and is not due to the high activation energy of dihydrogen $\left(\mathrm{H}_{2}\right)$ (see section $\mathrm{S} 2$ in the Supporting
Information).$^{7-10}$ Even with the growing number of reports on the use of supported/soluble Au hydrogenation catalysts, what determines the reaction mechanism on AuNPs is not well understood. Studies involving a Au model catalyst are still scarce, since many variables may affect the frequency factors of the surface species (see sections S3-S6 in the Supporting Information). The presence of additives, modifiers, and individual functionalized unsaturated substrates, as well as the size/distribution of AuNPs and the nature of the metalsupport interaction, can facilitate the dissociation of $\mathrm{H}_{2} \cdot{ }^{11-14}$ The term "naked" refers to catalysts (homogeneous, heterogeneous, or nano) surrounded by weak coordination species and

Received: February 6, 2017

Revised: $\quad$ March 1, 2017

Published: March 13, 2017 
hence containing easily accessible catalytically active coordination sites (metal surface or metal center). ${ }^{15-19}$

Scheme 1 displays an illustrative description of the most plausible hydrogenation pathways on an AuNP surface. The

Scheme 1. Possible Hydrogenation Mechanisms Operating at the AuNP Surfaces ( $\mathrm{M}=\mathrm{Al}, \mathrm{Ti}, \mathrm{Si}, \mathrm{Zr}, \mathrm{Ce}, \mathrm{B}=$ Ligand or Substrates with Heteroatoms): (i) Heterolytic $\mathrm{H}_{2}$ Activation; (ii) Homolytic $\mathrm{H}_{2}$ Activation; (iii) Generation of Subnanometer Au Catalytic Active Species; (iv) Outer Sphere
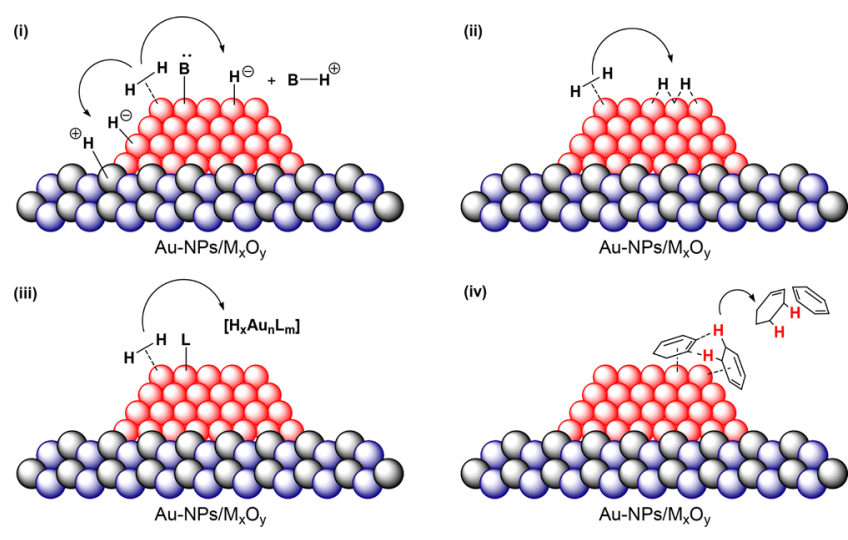

first and most commonly observed pathway (i) involves the ionic hydrogenation mechanism, in which the support, additive, or substrate collaborate with the Au surface sites, producing the direct heterolytic activation of $\mathrm{H}_{2}$ and the transfer of one proton to the support, additive, or substrate, with formation of the metal hydride. ${ }^{20-25}$ Among others, this mechanism has already been observed to operate with AuNPs supported onto inorganic oxides $\left(\mathrm{TiO}_{2}, \mathrm{Al}_{2} \mathrm{O}_{3}\right.$, and $\left.\left.\mathrm{CeO}_{2}\right)\right)^{26-28}$ AuNPs stabilized by secondary phosphine oxides (SPOs),,$^{29,30}$ and AuNP-catalyzed hydrogenations of substrates with heteroatoms in the reducible function ( $\mathrm{N}$-donor substrates, such as imines, nitriles, and quinolines). ${ }^{31,32}$ The second mechanism (ii) results in the dissociative chemisorption of $\mathrm{H}_{2}$ by the low-coordinated $\mathrm{Au}$ surface sites, with the formation of $\mathrm{H}$ atoms, which are in bridge positions sharing the low-coordinated $\mathrm{Au}$ atoms without inducing any significant deformation of the $\mathrm{Au}-\mathrm{Au}$ distances. ${ }^{33-35}$ Although this mechanism is quite probable (similar to that observed for other noble metals) from a theoretical point of view, ${ }^{36}$ it has not yet been firmly established experimentally.

The third mechanism (iii) consists of the activation of $\mathrm{H}_{2}$ with the ejection of $\mathrm{Au}-\mathrm{H}$ subnanometer clusters $\left(\mathrm{H}_{x} \mathrm{Au}_{m} \mathrm{~L}_{n}, \mathrm{~L}\right.$ $=$ ligand) as catalytically active species. Although this pathway has not yet been reported, it is well known that isolated Au atoms $^{37-40}$ and subnanometer clusters ${ }^{32,41-44}$ display improved performances regarding activity and selectivity on hydrogenations of butadienes, internal alkynes, and $\alpha, \beta$-unsaturated carbonyl compounds. Finally, and not yet experimentally proved, is the involvement of an outer-sphere mechanism (iv), similar to the disproportionation of cyclohexadiene observed for PdNP hydrogenation catalysts. ${ }^{45-48}$ Hence, more detailed experiments are crucial to obtain deeper information regarding mechanism(s) occurring during the hydrogenation reactions catalyzed by AuNPs and the pathways involved in the hydrogen/substrate activation, which will allow obtaining more efficient Au-based catalysts.
For this purpose, we have designed clean-surfacen, small-size, and well-distributed AuNPs supported directly on $\gamma-\mathrm{Al}_{2} \mathrm{O}_{3}$ (one of the most used oxide supports for $\mathrm{Au}$ ) and also on an ionic liquid (IL)-hybrid $\gamma-\mathrm{Al}_{2} \mathrm{O}_{3}$. The former catalyst displayed a strong support-metal interaction between the AuNPs and $\gamma$ $\mathrm{Al}_{2} \mathrm{O}_{3}$, whereas for the latter, a thin IL layer is acting as a cage for the AuNPs, avoiding direct contact between the AuNPs and $\gamma-\mathrm{Al}_{2} \mathrm{O}_{3}$ (Scheme 2). For the preparation of these model

Scheme 2. AuNPs Model Catalysts Prepared by Sputtering Deposition: $\mathrm{Au} / \gamma-\mathrm{Al}_{2} \mathrm{O}_{3}, \mathrm{Au} / \mathrm{B} 1(\mathrm{X}=\mathrm{Cl})$, and $\mathrm{Au} / \mathrm{B} 2(\mathrm{X}=$ $\mathrm{NTf}_{2}$ )

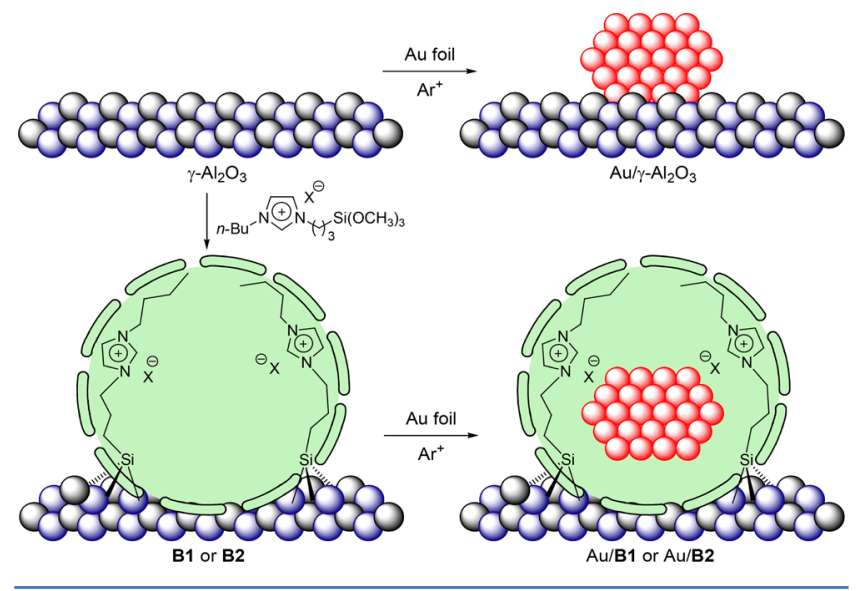

catalysts, we used a magnetron sputtering chamber that allows constant mixing of the solid support, which leads to the random deposition of the MNPs in all spatial planes of the inorganic oxide. In fact, the obtained AuNPs are small and uniformly well distributed on all of the distinct supports. Similarly to group 810 MNPs (Pd and RuNPs), ${ }^{40,41,49}$ the AuNPs generated by this technique are imprinted onto the most external layers of the inorganic oxide support. Their surfaces are clean and free of contaminants, since they are directly obtained from high-purity (99.999\%) metallic foils. The selective hydrogenation of conjugated dienes, alkynes, and $\alpha, \beta$-unsaturated carbonyl compounds (ketones and aldehydes) were used as probe reactions for testing the $6.6 \mathrm{~nm}$ face-centered cubic (fcc) metallic gold nanoparticle $(\mathrm{Au}(0) \mathrm{NP})$ model catalysts. The kinetic and deuterium labeling studies herein described provide experimental evidence that the $\mathrm{H}_{2}$ activation by AuNPs imprinted directly on $\gamma-\mathrm{Al}_{2} \mathrm{O}_{3}$ proceeds via an ionic hydrogenation mechanism (i), whereas a dissociative pathway (ii) operates on AuNP surfaces deposited on IL-hybrid $\gamma-\mathrm{Al}_{2} \mathrm{O}_{3}$. Moreover, an outer-sphere hydrogenation mechanism (iv) is also evidenced in the hydrogenation of 1,3-cylohexadiene by AuNP catalysts.

\section{RESULTS AND DISCUSSION}

2.1. Synthesis and Characterization of Supported Naked AuNPs. The hybrid support B1 (Scheme 2) was prepared by the reaction of $\gamma-\mathrm{Al}_{2} \mathrm{O}_{3}$ with 1-n-butyl-3(trimethoxysilylpropyl)imidazolium chloride. The hybrid support B2 was afford by simple B1 anion exchange with $\mathrm{LiNTf}_{2}$ ( $\mathrm{NTf}_{2}=$ bis(trifluoromethylsulfonyl)imide). ${ }^{48,49}$

The $\gamma-\mathrm{Al}_{2} \mathrm{O}_{3}$ and the IL-hybrid $\gamma-\mathrm{Al}_{2} \mathrm{O}_{3}$ (B1 and B2) were decorated with AuNPs using a 3D mixing sputtering device (Scheme 2). ${ }^{48-50}$ The as-prepared catalysts $\left(\mathrm{Au} / \gamma-\mathrm{Al}_{2} \mathrm{O}_{3}, \mathrm{Au} /\right.$ B1, and $\mathrm{Au} / \mathrm{B2}$ ) were characterized by solid-state cross- 
Table 1. Summary of the Physical and Chemical Characteristics of the $\mathrm{Au} / \gamma-\mathrm{Al}_{2} \mathrm{O}_{3}, \mathrm{Au} / \mathrm{B} 1$, and $\mathrm{Au} / \mathrm{B} 2 \mathrm{Catalysts}$

\begin{tabular}{|c|c|c|c|c|c|c|c|}
\hline entry & catalyst & $\mathrm{IL}^{a} / \mathrm{mmol} \mathrm{g}^{-1}$ & $\mathrm{Au}^{b} / \mathrm{wt} \%$ & $\phi_{\mathrm{AuNPs}}{ }^{c} / \mathrm{nm}$ & $S_{\mathrm{BET}}^{d} / \mathrm{m}^{2} \mathrm{~g}^{-1}$ & $\phi_{\text {pore }} d / \mathrm{nm}$ & $\mathrm{Au} 4 \mathrm{f}_{7 / 2}{ }^{e} / \mathrm{eV}$ \\
\hline 1 & $\mathrm{Au} / \gamma-\mathrm{Al}_{2} \mathrm{O}_{3}$ & & $0.34 \pm 0.03$ & $6.7 \pm 2.0$ & 194 & 7.0 & 83.8 \\
\hline 2 & $\mathrm{Au} / \mathrm{B} \mathbf{1}$ & 0.38 & $0.34 \pm 0.04$ & $6.5 \pm 2.2$ & 142 & 6.3 & 83.6 \\
\hline 3 & $\mathrm{Au} / \mathrm{B} 2$ & 0.35 & $0.32 \pm 0.04$ & $6.6 \pm 1.8$ & 143 & 6.2 & 83.7 \\
\hline
\end{tabular}

${ }^{a}$ Determined by CHN elemental analysis. ${ }^{b}$ Determined by X-ray fluorescence (XRF) spectrometry. ${ }^{c}$ Determined by transmission electron microscopy (TEM). ${ }^{d}$ Determined by the Brunauer-Emmett-Teller (BET) multipoint method and Barrett-Joyner-Halenda (BJH) method. ${ }^{e}$ Determined by X-ray photoelectron spectroscopy (XPS).

polarization magic angle spinning nuclear magnetic resonance (CP-MAS NMR), Fourier transform infrared (FT-IR), $\mathrm{N}_{2}$ physisorption, transmission electron microscopy (TEM), $\mathrm{CHN}$ elemental analysis, scanning electron microscopy with energy-dispersive X-ray spectroscopy (SEM-EDS), X-ray diffraction (XRD), X-ray fluorescence (XRF), Rutherford backscattering spectrometry (RBS), and X-ray photoelectron spectroscopy (XPS).

${ }^{13} \mathrm{C}$ and ${ }^{29} \mathrm{Si} \mathrm{CP}-\mathrm{MAS}$ NMR analysis revealed the presence of unreacted $\mathrm{Si}-\mathrm{C}$ bonds and the existence of $\mathrm{T}^{1}$ and $\mathrm{T}^{2}$ species, thus confirming that, even under the acidic reaction conditions, the IL cation moiety has been effectively supported by the grafting method (see Tables S5 and S6 and Figures S3 and S4 in the Supporting Information). The presence of the IL moieties (cation and anion) in the $\mathrm{Au} / \mathrm{IL}$-hybrid $\gamma-\mathrm{Al}_{2} \mathrm{O}_{3}$ was confirmed by the observation of their characteristic IR bands (see Table S7 and Figure S5 in the Supporting Information). The $\mathrm{N}_{2}$ physisorption isotherms of $\mathrm{Au} / \gamma-\mathrm{Al}_{2} \mathrm{O}_{3}$ and $\mathrm{Au} / \mathrm{IL}$ hybrid $\gamma-\mathrm{Al}_{2} \mathrm{O}_{3}(\mathrm{Au} / \mathrm{B1}$ and $\mathrm{Au} / \mathrm{B2})$ exhibited similar type IV isotherm patterns with surface areas between 142 and $194 \mathrm{~m}^{2}$ $\mathrm{g}^{-1}$ and pore diameters between 6.2 and $7.0 \mathrm{~nm}$ (Table 1 and Figure 1a,b).

The surface area, pore volume, and pore diameter values slightly decreased in the catalysts bearing ILs ( $\mathrm{Au} / \mathrm{B1}$ and $\mathrm{Au} /$ B2), indicating that ILs partially fill the $\gamma-\mathrm{Al}_{2} \mathrm{O}_{3}$ pores. These findings are of crucial importance, since they suggest the presence of a homogeneous and well-dispersed IL layer on the B1 and B2 supports, which can provide efficient stabilization for AuNPs. Similar characteristics were obtained in the immobilization of a functionalized imidazolium IL on $\mathrm{SiO}_{2}$ used for stabilization of RuNPs and FeRuNPs. ${ }^{51,52}$

As expected, the metal amount $(\sim 0.3$ wt $\%)$, shape, size $(\sim 6.6 \mathrm{~nm})$, and distribution of the AuNPs are similar in all catalysts, since identical sputtering conditions were employed (Table 1 and Figure 1). The XRD analysis displayed the typical pattern of the $\mathrm{fcc} \mathrm{Au}(0)$ lattice with characteristic diffraction peaks at $2 \theta=38.1,44.2,64.6,77.5,81.4^{\circ}$, corresponding to the (111), (200), (220), (311), and (222) planes, respectively (Figure 1c). Interestingly, TEM and SEM-EDS analyses showed well-distributed and small AuNPs on the $\mathrm{Au} / \mathrm{Al}_{2} \mathrm{O}_{3}$, $\mathrm{Au} / \mathrm{B1}$, and $\mathrm{Au} / \mathrm{B} 2$ catalysts with mean diameters of $6.7,6.5$, and $6.6 \mathrm{~nm}$, respectively (Table 1 and Figure $1 \mathrm{~d}, \mathrm{e}$ ). In addition, the RBS results clearly indicate that in all cases the metal concentration is much higher at the most external layers $(\sim 10$ $\mathrm{nm}$ ) of $\mathrm{Au} / \gamma-\mathrm{Al}_{2} \mathrm{O}_{3}$ and $\mathrm{Au} / \mathbf{B 1}$ and $\mathrm{Au} / \mathbf{B 2}$ catalyst models and, therefore, the accessibility of the reactants to the AuNP active sites is expected to be superior in comparison to $\mathrm{Au}$ catalysts synthesized by chemical methods (Figure 1f). A similar depth profile has already been observed for PdNPs imprinted in IL-hybrid $\mathrm{SiO}_{2}$ supports. ${ }^{45,46}$ These results suggest that such characteristics are unaffected by the nature of the support $\left(\gamma-\mathrm{Al}_{2} \mathrm{O}_{3}\right.$ or hybrid $\gamma-\mathrm{Al}_{2} \mathrm{O}_{3}$ containing hydrophilic or hydrophobic moieties). It has already been demonstrated that, depending on sputtering parameters, it is possible to obtain AuNPs of small sizes $(1-10 \mathrm{~nm})$ on pure $\mathrm{IL})^{53-55}$ pure inorganic oxides $\left(\mathrm{TiO}_{2}\right),{ }^{56}$ and ILs supported on inorganic oxides (ILs dispersed on $\mathrm{TiO}_{2}$ ). ${ }^{57}$ It is also worth noting that, in all cases, the AuNP surface is exclusively composed of metallic gold $(\mathrm{Au}(0))$, as determined by XPS (Figure 1g). Furthermore, there is a positive shift in the Au binding energies (for instance, see $\mathrm{Au} 4 \mathrm{f}$ components in Table 1 and Figure 1 and Au valence band (VB) in Figure S6 in the Supporting Information ) of the AuNPs onto $\gamma-\mathrm{Al}_{2} \mathrm{O}_{3}$, with respect to those on the IL-hybrid $\gamma$ $\mathrm{Al}_{2} \mathrm{O}_{3}$ (B1 and $\mathbf{B 2}$ ), suggesting that, in the latter case, the interaction of the AuNPs with the $\gamma-\mathrm{Al}_{2} \mathrm{O}_{3}$ support was decreased by the presence of the IL pair layers. ${ }^{58,59}$ Therefore, it is much more likely that the IL moiety forms an IL cage, surrounding the AuNPs, akin to that already observed for other metal catalysts on IL-containing supports. ${ }^{45,60,61}$

The complete exchange of $\mathrm{Cl}^{-}$by $\mathrm{NTf}_{2}{ }^{-}$was confirmed by XPS analysis of the hybrid support $\mathbf{B 2}$ and also on the supported AuNP-containing material Au/B2 (Figure S7 in the Supporting Information). XPS analyses were also used to estimate the thickness of the IL layers, and the presence of 10 and $7 \mathrm{Au}$ atoms per IL pair in $\mathrm{Au} / \mathrm{B} 1$ and $\mathrm{Au} / \mathrm{B2}$, respectively, was confirmed (see Table S8 and Figure S7 in the Supporting Information). Although these IL layers are thin, previous reports on hydrogenation processes described that similar thin IL layers produce the best compromise between the hydrogenation activity and the selectivity enhacement by IL substrate/product discrimination. ${ }^{55,57,60}$ These behaviors were ascribed to the effect on the concentration of reactants available at the catalytic center by the distinct reactant solubility/ miscibility in the $\mathrm{IL}^{62-64}$ or to the IL interaction with specific catalytically active particle sites: i.e., a proposed ligand-like interaction with different surface sites on Pt or PdNPs by the use of the IL 1-n-butyl-3-methylimidazolium bis(trifluoromethylsulfonyl)imide (BMI-NTf $\left.)_{2}\right)^{60,62,65}$ The IL pair interaction with the AuNPs was further confirmed by comparing the XPS spectra of B1, B2, Au/B1, and Au/B2 (see Figure S8 in the Supporting Information). For the supports bearing chloride as an anion, a negative shift of $2.7 \mathrm{eV}$ in the $\mathrm{Cl}$ $2 p$ region was observed (198.3 and $195.6 \mathrm{eV}$ for $\mathbf{B 1}$ and $\mathrm{Au} /$ B1, respectively). In the case of $\mathrm{NTf}_{2}$-bearing supports, the $\mathrm{F} 1 \mathrm{~s}$ regions of $\mathbf{B 2}$ and $\mathrm{Au} / \mathbf{B} 2$ displayed a peak related to uncoordinated $\mathrm{NTf}_{2}(688.8 \mathrm{eV}){ }^{66}$ and a new component appeared at $685.4 \mathrm{eV}$ for $\mathrm{Au} / \mathrm{B2}$. These behaviors were ascribed to the interaction of the contact ion pairs ${ }^{67}$ of the $\mathrm{IL}$ with the AuNPs, similar to that observed for thiol-modified AuNPs. ${ }^{58}$

2.2. Catalytic Hydrogenation Properties of Supported Naked AuNPs. The hydrogenation of 1,3-cyclohexadiene (1) was used as a probe to check the catalytic properties of the asprepared supported AuNPs (Table 2). It is clear that there is an influence of the support on the catalytic performance of the imprinted AuNPs. $\mathrm{Au} / \gamma-\mathrm{Al}_{2} \mathrm{O}_{3}$ is more active than $\mathrm{Au} / \mathbf{B} \mathbf{1}$ and $\mathrm{Au} / \mathbf{B} 2$ under identical reaction conditions, whereas $\mathrm{Au} / \mathbf{B} 2$ is 
a)

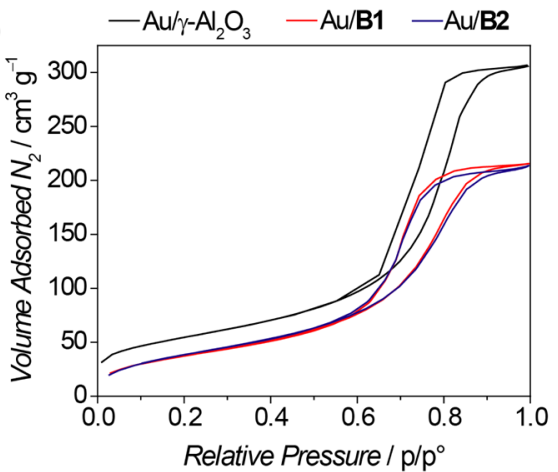

d)

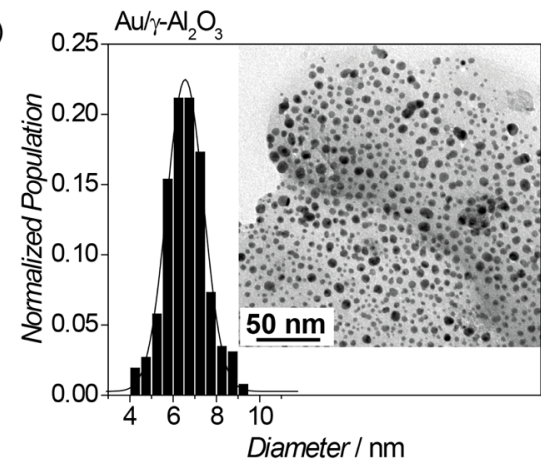

e) $\mathrm{Au} / \gamma-\mathrm{Al}_{2} \mathrm{O}_{3}$

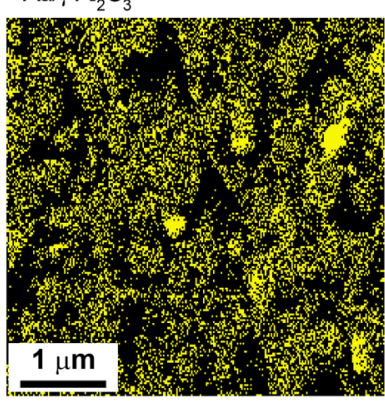

Au/B1

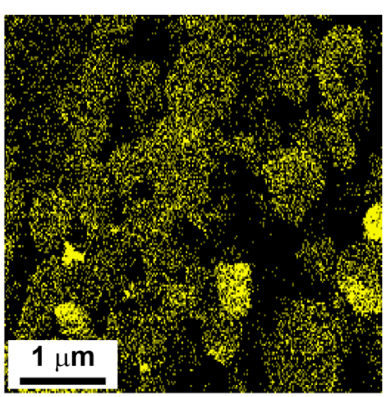

$\mathrm{Au} / \mathrm{B2}$
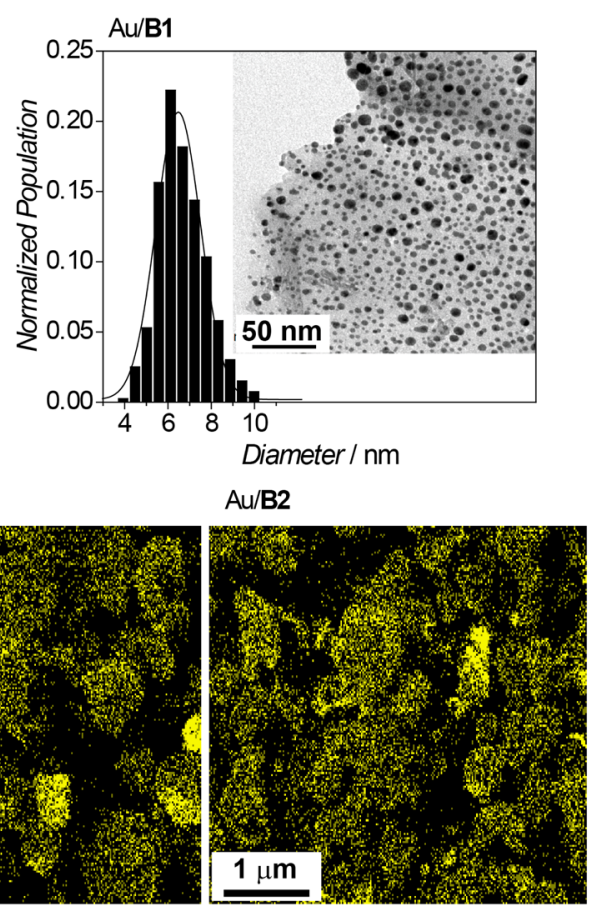

Diameter / nm

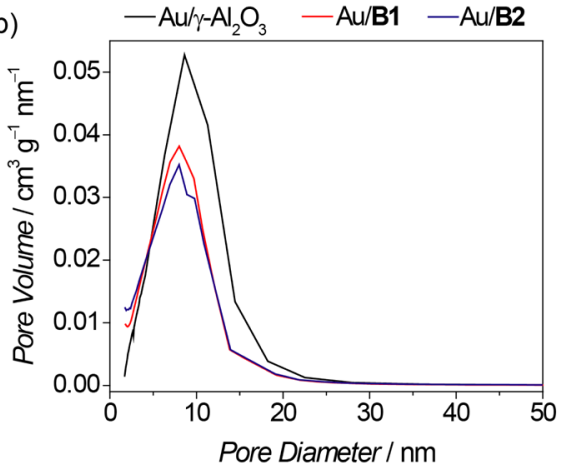

c) $-\gamma-\mathrm{Al}_{2} \mathrm{O}_{3}-\mathrm{Au} / \gamma-\mathrm{Al}_{2} \mathrm{O}_{3}-\mathrm{Au} / \mathrm{B} 1-\mathrm{Au} / \mathrm{B} 2$
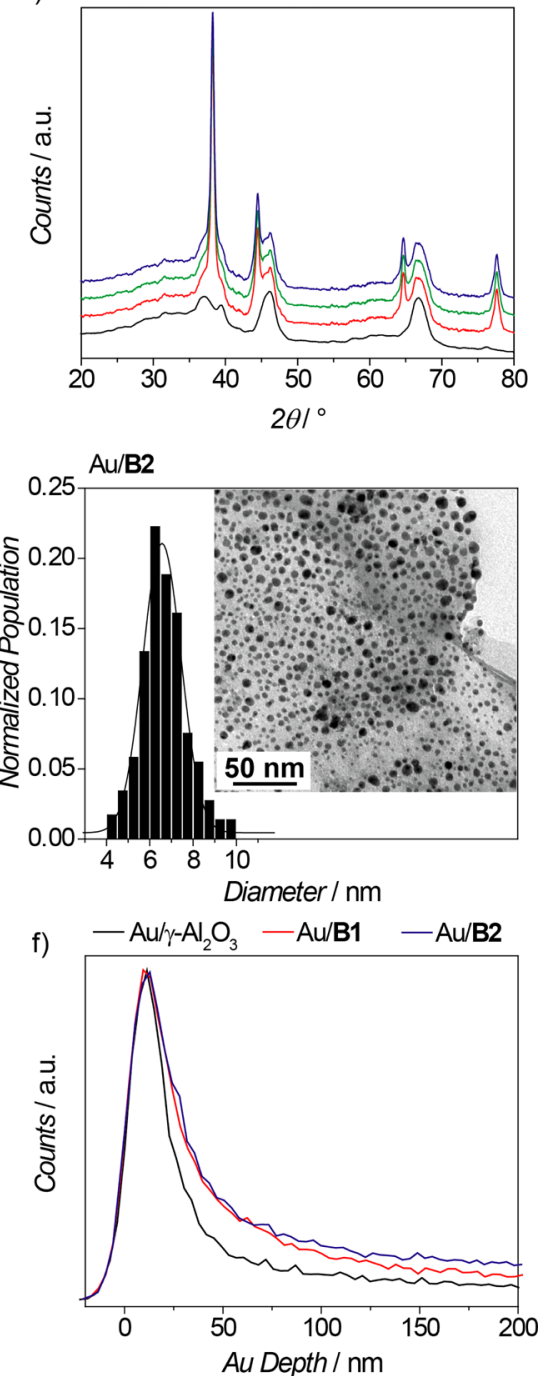

g)
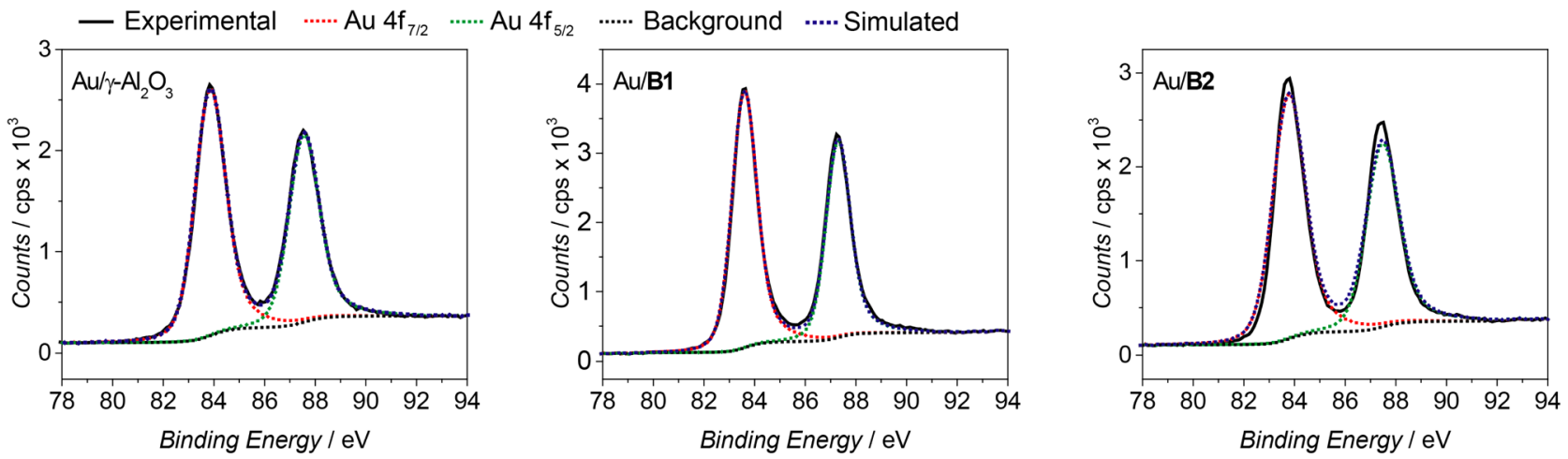

Figure 1. Characterization of the AuNPs model catalysts prepared by sputtering deposition: (a) BET $\mathrm{N}_{2}$ physisorption isotherms; (b) BJH pore diameter distribution; (c) XRD patterns; (d) TEM images and size histograms; (e) EDS-SEM images; (f) RBS depth-profile distribution of Au in the supports; (g) Au 4f XPS spectra.

slightly more selective to cyclohexene (2) formation (Table 2, entries 3, 6 and 9). It is also noteworthy that $\mathrm{Au} / \mathbf{B 1}$ and $\mathrm{Au} / \mathbf{B 2}$ are almost inactive at lower termperatures $\left(50{ }^{\circ} \mathrm{C}\right)$ and lower pressures ( 5 bar of $\mathrm{H}_{2}$ ) (Table 2, entries 4, 5, 7 and 8), while $\mathrm{Au} / \gamma-\mathrm{Al}_{2} \mathrm{O}_{3}$ exhibits higher hydrogenation activities (Table 2, entries 1 and 2). This fact indicates a strong metal-support interaction (SMSI) and probably a distinct $\mathrm{H}_{2}$ activation pathway (see below). More interestingly, in comparison to the results obtained using $\mathrm{H}_{2}$ and $\mathrm{D}_{2}$, a change in the kinetic isotopic effect (KIE) and cyclohexene (2) selectivity was observed for the AuNPs catalysts surrounded by IL (Scheme 3 and Table $S 9$ and Figure $S 9$ in the Supporting Information). The KIE observed for the $\mathrm{Au} / \gamma-\mathrm{Al}_{2} \mathrm{O}_{3}$ catalyst $\left(k_{\mathrm{H}} / k_{\mathrm{D}}=1.1\right)$ is comparable to those observed in $\mathrm{Pd} / \mathrm{Al}_{2} \mathrm{O}_{3},{ }^{48} \mathrm{Pd} / \mathrm{SiO}_{2},{ }^{45,46}$ and $\mathrm{Pd} / \mathrm{C}^{1}$ catalysts in similar hydrogenation reactions and is consistent with the zero-point energy difference between 
Table 2. Selective Hydrogenation of 1,3-Cyclohexadiene Catalyzed by $\mathrm{Au} / \gamma-\mathrm{Al}_{2} \mathrm{O}_{3}, \mathrm{Au} / \mathrm{B1}$, and $\mathrm{Au} / \mathrm{B} 2$

\begin{tabular}{|c|c|c|c|c|c|c|c|}
\hline entry ${ }^{a, b}$ & catalyst & $T /{ }^{\circ} \mathrm{C}$ & $P_{\mathrm{H} 2} / \mathrm{bar}$ & $2 / \%$ & $3 / \%$ & $4 / \%$ & $\mathrm{TOF}^{c} / \mathrm{min}^{-1}$ \\
\hline 1 & $\mathrm{Au} / \gamma-\mathrm{Al}_{2} \mathrm{O}_{3}$ & 50 & 5 & 88 & 9 & 1 & 0.7 \\
\hline 2 & $\mathrm{Au} / \gamma-\mathrm{Al}_{2} \mathrm{O}_{3}$ & 100 & 5 & 86 & 10 & 4 & 1.0 \\
\hline 3 & $\mathrm{Au} / \gamma-\mathrm{Al}_{2} \mathrm{O}_{3}$ & 100 & 25 & 89 & 1 & 10 & 6.9 \\
\hline 4 & $\mathrm{Au} / \mathrm{B} \mathbf{1}$ & 50 & 5 & & & & $<0.01$ \\
\hline 5 & $\mathrm{Au} / \mathrm{B} \mathbf{1}$ & 100 & 5 & 92 & 7 & 1 & 0.1 \\
\hline 6 & $\mathrm{Au} / \mathrm{B} \mathbf{1}$ & 100 & 25 & 93 & 2 & 5 & 3.2 \\
\hline 7 & $\mathrm{Au} / \mathbf{B} 2$ & 50 & 5 & & & & $<0.01$ \\
\hline 8 & $\mathrm{Au} / \mathbf{B} 2$ & 100 & 5 & 91 & 8 & 1 & 0.1 \\
\hline 9 & $\mathrm{Au} / \mathbf{B} 2$ & 100 & 25 & 96 & 2 & 2 & 4.1 \\
\hline
\end{tabular}

${ }^{a}$ Reaction conditions: Au $(0.5 \mu \mathrm{mol}), 1,3$-cyclohexadiene $/ \mathrm{Au}=250, n$-hexane $(5 \mathrm{~mL})$, and $250 \mathrm{rpm} .{ }^{b}$ Selectivity determined by GC analysis at $>99 \%$ conversion. ${ }^{c} \mathrm{TOF}=(\mathrm{mol}$ of substrate converted $) /((\mathrm{mol}$ of Au surface $\left.) \mathrm{min})\right)$ calculated from the slope of plots of TON vs time at low substrate conversions. $^{70}$

Scheme 3. Hydrogenation of 1,3-Cyclohexadiene Catalyzed by $\mathrm{Au} / \gamma-\mathrm{Al}_{2} \mathrm{O}_{3}, \mathrm{Au} / \mathrm{B} 1$, and $\mathrm{Au} / \mathrm{B} 2$ under $\mathrm{H}_{2} / \mathrm{D}_{2}$

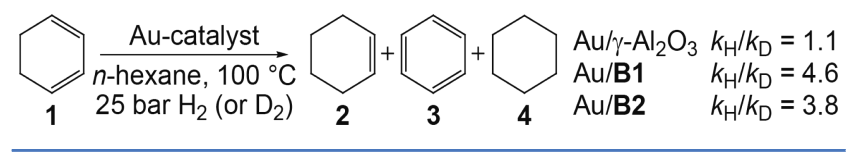

isotopic isomers. Therefore, this is an indication that the $\mathrm{H}_{2} / \mathrm{D}_{2}$ activation is not the rate-determining step ( $\mathrm{RDS}$ ) of the hydrogenations catalyzed by $\mathrm{Au} / \gamma-\mathrm{Al}_{2} \mathrm{O}_{3}$, but rather an involvement of hydrogen bond/formation pathways during the reaction mechanism. Similar behaviors were reported for other Au-catalyzed processes $\left(k_{\mathrm{H}} / k_{\mathrm{D}}=1.5-2.0\right)^{32,68,69}$ and hydrogenation of 1,3-cyclohexadiene by PdNPs supported on similar IL-hybrid supports $\left(k_{\mathrm{H}} / k_{\mathrm{D}}=1.3\right.$ and 2.0 for $\mathrm{Al}_{2} \mathrm{O}_{3}{ }^{48}$ and $\mathrm{SiO}_{2},{ }^{45,46}$ respectively).

Conversely, high KIEs were obtained by the Au/IL-hybrid $\gamma$ $\mathrm{Al}_{2} \mathrm{O}_{3}$ catalysts $\left(k_{\mathrm{H}} / k_{\mathrm{D}}=4.6\right.$ and 3.8 with $\mathrm{Au} / \mathrm{B1}$ and $\mathrm{Au} / \mathbf{B} 2$, respectively), indicating that, in these cases, the $\mathrm{H}_{2} / \mathrm{D}_{2}$ activation is occurring during the RDS. Moreover, the formation of cyclohexene- $d_{2}^{1,2}\left(2-d_{2}{ }^{1,2}\right)$ and cyclohexene- $d_{2}{ }^{1,4}$ $\left(2-d_{2}^{1,4}\right)$ products $(1,2-/ 1,4$-addition ratios of $4.5,4.6$, and 5.3 for $\mathrm{Au} / \mathrm{Al}_{2} \mathrm{O}_{3}, \mathrm{Au} / \mathbf{B 1}$, and $\mathrm{Au} / \mathbf{B} 2$, respectively) suggests the involvement of $\pi$-allyl metastable intermediates in the reaction mechanism, and the formation of clohexene- $d_{0}\left(2-d_{0}\right)$ and benzene- $d_{0}\left(3-d_{0}\right)$ by disproportionation of 1,3-cyclohexadiene (1) under $\mathrm{D}_{2}$ suggests the occurrence of the outer-sphere mechanism (Scheme 1, pathway iv). The existence of 1,3cyclohexadiene (1) disproportionation is a clear indication of the involvement of Au-heterotopic species (Au-NP surfaces) as the catalytically active sites, ${ }^{47}$ a fact that discards the presence of subnanometer Au clusters as active species (Scheme 1, pathway iii). In summary, the IL thin layer acts as a catalytically active membranelike device, influencing the frequency factor of active species on the Au surface and thus changing the AuNP catalytic performance and even the reaction mechanism and RDS.

The scope of the most selective catalyst $(\mathrm{Au} / \mathrm{B2})$ was evaluated by carrying out the hydrogenation of 1,3-dienes with distinct degrees of substitution, alkenes conjugated with an arene system, internal aliphatic alkynes, $\alpha, \beta$-unsaturated aldehydes, and $\alpha, \beta$-unsaturated ketones. In general, our catalytic system, $\mathrm{Au} / \mathbf{B 2}$, displayed high selectivities in a broad range of hydrogenations under 25 bar of $\mathrm{H}_{2}$ and 100
${ }^{\circ} \mathrm{C}$ (Table 3 and Table S10 and Figure S10 in the Supporting Information). The high alkene selectivities (96 to >99\%) and activity orders obtained are related to the steric congestion of the double $\mathrm{C}=\mathrm{C}$ bonds and, thus, the coordination ability to the Au surface: $8>1>13 \approx 5>17 \approx 20$ (Table 3, entries $1-$ $6)$. In the hydrogenation of a primary alkene conjugated with an arene system (24), much lower activity was obtained (Table 3 , entry 7) in comparison to 1,3-dienes, thus suggesting that substrate adsorption/activation is occurring during the RDS. The hydrogenation of an internal aliphatic alkyne (26) achieved an selectivity of $99 \%$ to the internal alkene with a $Z: E$ ratio of 2.6. The activity in the hydrogenation of internal alkyne is similar to those obtained with internal 1,3-dienes ( 1 and 5), which indicates that the reactivities of 1,3-dienes and internal alkynes should be very similar (Table 3 , entry 8 ). The double bond is hydrogenated with high selectivity in $\alpha, \beta$ unsaturated carbonyl compounds (Table 3, entries 9-12), and the activities obtained are related to the electronic and steric effects of the substrates. These results confirm that the coordination ability of the substrate to the Au surface plays a significant role in the reaction rate.

2.3. Hydrogenation Kinetics by Supported Naked AuNPs. According to the Horiuti-Polanyi mechanism, the alkene hydrogenation involves three steps: (i) alkene adsorption on the metal surface catalyst saturated with hydrogen, (ii) hydrogen migration to the $\beta$ carbon of the alkene with formation of a $\sigma$-bond between the metal and $\alpha$-C, and finally (iii) reductive elimination of the alkane. ${ }^{71}$ AuNPs, in contrast to group 8-10 metals, exhibit an increasing capacity of $\mathrm{H}_{2}$ dissociation and $\mathrm{H}_{2}$ uptake with increasing temperature. ${ }^{72}$ $\mathrm{H}_{2}$ adsorption is limited by kinetic factors at moderate temperatures $\left(25-100{ }^{\circ} \mathrm{C}\right)$ with two possible kinetic scenarios: (a) low concentration of adsorbed hydrogen due to the limited $\mathrm{H}_{2}$ dissociation and (b) $\mathrm{H}_{2}$ dissociation favored and high concentration of adsorbed atomic $\mathrm{H}^{73}$

Given the evidence obtained by the kinetic isotopic effects and catalytic experiments, the kinetics of the 1,3-cyclooctadiene (5) hydrogenation was investigated using a modified Langmuir-Hinshelwood kinetic model. ${ }^{14,35,73,74}$ The application of the linear form of the Langmuir-Hinshelwood equation suggests that under our reaction conditions (15-30 bar of $\mathrm{H}_{2}$ and $75-150{ }^{\circ} \mathrm{C}$ ), the RDS consists of the surface reaction between competitively adsorbed 1,3-cyclooctadiene (5) and $\mathrm{H}_{2}$ 
Table 3. Selective Hydrogenations Catalyzed by Au/B2

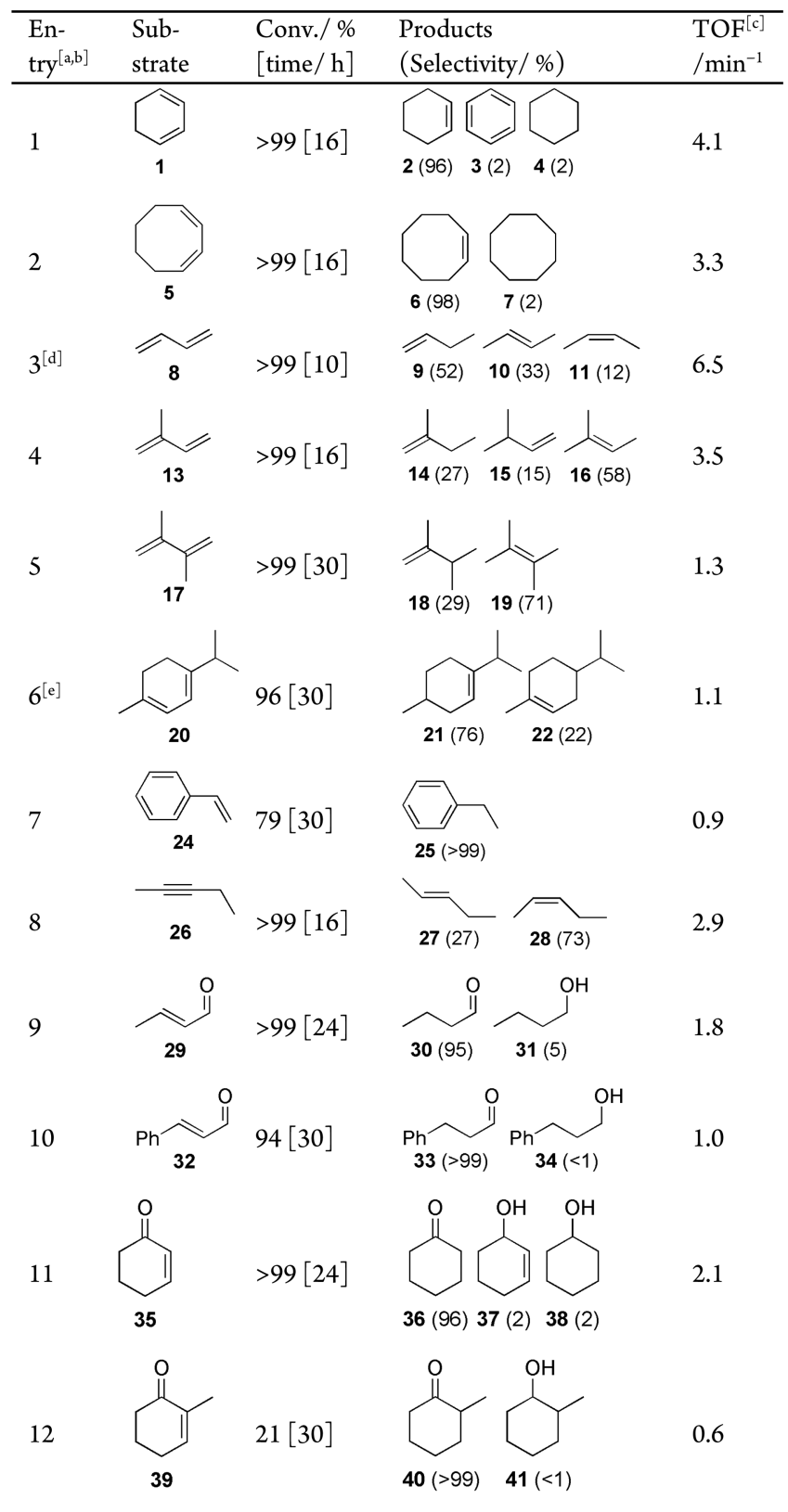

${ }^{a}$ Reaction conditions: $\mathrm{Au}(0.5 \mu \mathrm{mol})$, substrate $/ \mathrm{Au}=250,5 \mathrm{~mL}$ of solvent ( $n$-hexane for dienes and alkynes, and $m$-xylene for $\alpha, \beta$ unsaturated carbonyl compounds), 25 bar of $\mathrm{H}_{2}, 100^{\circ} \mathrm{C}$, and $250 \mathrm{rpm}$. ${ }^{b}$ Selectivity determined by GC analysis. ${ }^{c} \mathrm{TOF}=(\mathrm{mol}$ of substrate converted $) /((\mathrm{mol}$ of Au surface $) \mathrm{min})$ calculated from the slope of

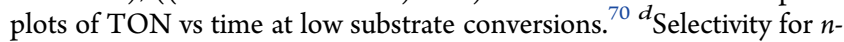
butane (12): $3 \%$. ${ }^{e}$ Selectivity for 1-isopropyl-4-methylcyclohexane (23): $2 \%$.

molecules on active sites of the same nature. Under these conditions, the 1,3-cyclooctadiene (5) hydrogenation rate is independent (zero order) of the fraction of catalyst surface covered by the substrate and $\mathrm{H}_{2}$ (see Tables $\mathrm{S} 11$ and $\mathrm{S} 12$ and Figures S11-S14 in the Supporting Information). The reaction kinetics is different at lower pressures (10 bar) and temperatures $\left(50{ }^{\circ} \mathrm{C}\right)$, which is dependent on the fraction of $\mathrm{Au}$ surface covered by 1,3 -diene and $\mathrm{H}_{2}$. This probably occurs by the lower fraction of $\mathrm{H}$ atoms absorbed under these conditions, which highlights the effect of the IL membrane on the concentration of the species at the Au surface. This behavior was previously observed in hydrogenation reactions catalyzed by $\mathrm{PdNPs}^{45}$ and indicates again the presence of IL thin layers in the support. Therefore, the small thinness of these IL layers excluded the involvement of mass transfer limitations during the catalytic process, and it increases the solubility of the $\mathrm{H}_{2}$ at moderate pressures $(>10 \mathrm{bar})$ and temperatures $\left(>50{ }^{\circ} \mathrm{C}\right)$.

Scheme 4 displays the proposed mechanism for the 1,3cyclooctadiene (5) hydrogenation catalyzed by Au/B2. This

Scheme 4. Proposed Mechanism for the Selective Hydrogenation of 1,3-Cyclooctadiene Catalyzed by Au/B2

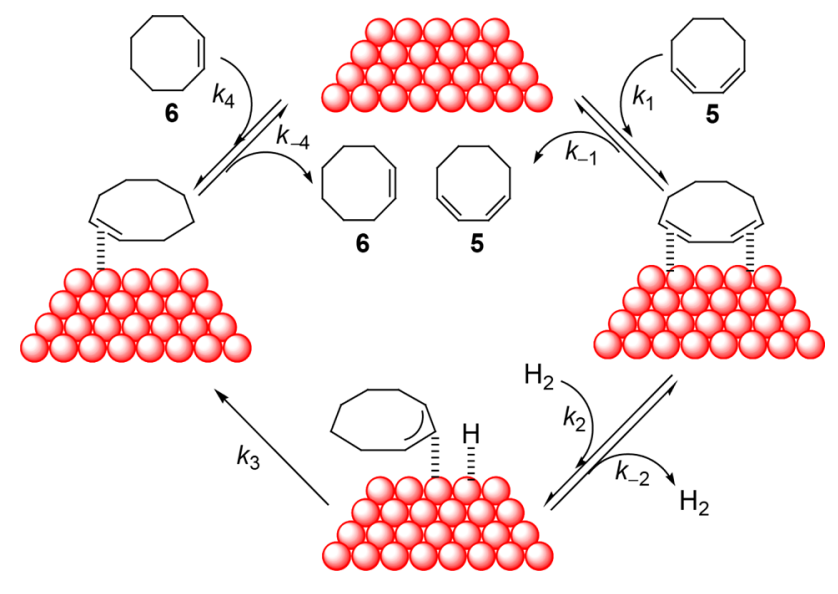

mechanism is based on the Horiuati-Polanyi mechanism for the hydrogenation of alkenes but includes an additional step: (iv) decoordination of the monoene, i.e., cyclooctene (6) (Scheme 4 and section S10 in the Supporting Information). A plot of the natural $\log$ of $k_{\mathrm{r}}$ against the inverse of different reaction temperatures allowed the estimation of the apparent activation energy $\left(E_{\mathrm{a} \text {-app }}\right)$ for the 1,3-cyclooctadiene (5) hydrogenation (Figure 2). The observed Arrhenius plot exhibits

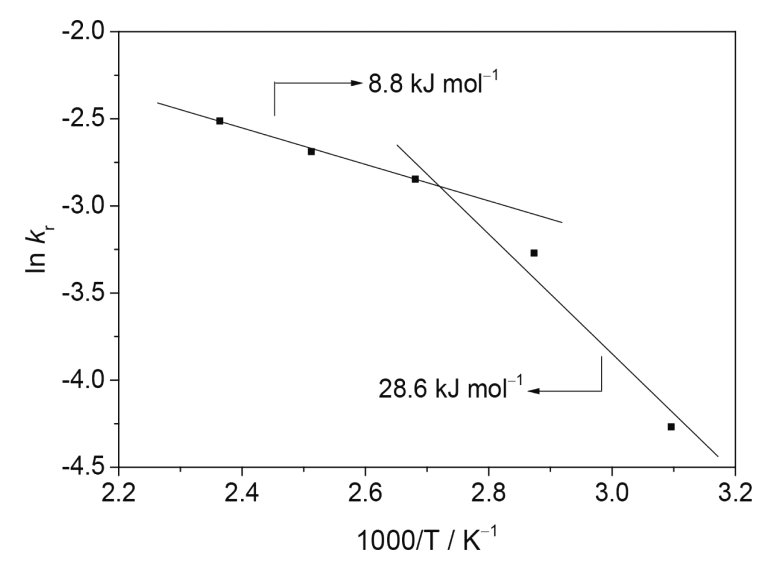

Figure 2. Arrhenius plot of the selective hydrogenation of 1,3cyclooctadiene catalyzed by $\mathrm{Au} / \mathbf{B} 2$.

a convex curve, although quite anomalously, it expresses the effect of the temperature on the $\mathrm{H}_{2}$ and substrate competitive adsorption/activation on the same active sites and the presence of absorbed mestastable $\pi$-allyl as reactive intermediates on the AuNP surface $\left(k_{\mathrm{r}}=k_{3} K_{2}\right)$. At lower temperatures $\left(50-100^{\circ} \mathrm{C}\right)$, this reactive intermediate predominates and exhibits a preexponential factor $(A)$ of $658 \mathrm{~s}^{-1}$. However, as the temperature is raised $\left(100-150{ }^{\circ} \mathrm{C}\right)$, the $\pi$-allyl intermediate dissociates, 
which affects the reaction rate, leading to a small $A$ value (1.03 $\left.\mathrm{s}^{-1}\right)$. The $E_{\mathrm{a} \text {-app }}$ value at low temperatures $\left(29 \mathrm{~kJ} \mathrm{~mol}^{-1}\right)$ is similar to those observed for PdNP catalysts supported on similar supports $\left(32 \mathrm{~kJ} \mathrm{~mol}^{-1}\right)$, but the $E_{\mathrm{a} \text {-app }}$ value at high temperatures $\left(9 \mathrm{~kJ} \mathrm{~mol}^{-1}\right)$ is much lower for $\mathrm{Au}$ than for $\mathrm{Pd}$ $\left(24 \mathrm{~kJ} \mathrm{~mol}^{-1}\right){ }^{45}$ Considering thermodynamics, higher temperatures favored the hydrogen desorption and the reduction of the $\mathrm{H} / \mathrm{M}$ ratio for group 8-10 metals. Interestingly, the $\mathrm{H} / \mathrm{Au}$ ratio is maintained, owing to the kinetic factors: i.e., higher temperatures facilitate the $\mathrm{H}_{2}$ dissociation on AuNPs and the $\mathrm{H} / \mathrm{Au}$ ratio reaches a maximum at a certain temperature. ${ }^{72}$ Therefore, these studies suggest that $\mathrm{Au}$ is more efficient (lower $E_{\mathrm{a}}$ ) than group 8-10 MNPs for hydrogenation reactions at moderate to high temperatures $\left(75-150{ }^{\circ} \mathrm{C}\right)$. Finally, the selectivity is not modified by changing any parameter (substrate/product ratio, hydrogen pressure, or reaction temperature), which emphasizes again that the selectivity of $\mathrm{Au} / \mathrm{IL}$-hybrid $\gamma-\mathrm{Al}_{2} \mathrm{O}_{3}$ is inherent to the $\mathrm{Au}(0) \mathrm{NPs}$ with IL thin layers and can be attributed to a confined-like environment.

\section{CONCLUSIONS}

The sputtering deposition approach allowed the synthesis of clean-surface $\sim 6.6 \mathrm{~nm}$ fcc $\mathrm{Au}(0) \mathrm{NPs}$ recovered by IL-like membranes (IL thin layers) for application as hydrogenation model catalysts. These catalytic systems are active for the hydrogenation of a wide scope of substrates with high selectivity. The distinct hydrogenation pathways (heterolytic, homolytic, and outer sphere) displayed by the AuNP surfaces are directly related to the nature of the support. More specifically, with the AuNP location, those interacting directly with the oxide support display a synergic behavior in which the $\mathrm{H}_{2}$ is heterolytically activated by both catalyst components (support and AuNPs). However, the AuNPs located preferentially away from the oxide support, i.e. in the IL cage, present the reactivity of naked AuNPs. The IL-like membrane acts in two ways: (1) by controlling the access of the reagents to the AuNP surfaces and (2) by avoiding the interaction between AuNPs and $\mathrm{Al}_{2} \mathrm{O}_{3}$, thus exchanging the reaction kinetics. We present evidence for the (1) heterolytic activation of $\mathrm{H}_{2}$ by collaboration of AuNPs and $\mathrm{Al}_{2} \mathrm{O}_{3},(2)$ homolytic activation of $\mathrm{H}_{2}$ occurring in AuNPs surrounded by IL thin layers, (3) an outer-sphere mechanism (disproportionation of 1,3-cyclohexadiene) operating on AuNPs, and (4) better gold efficiency on comparison of its hydrogenation $E_{\mathrm{a}}$ (moderate to high temperatures) to group 8-10 metals. These studies open new opportunities for the industrial application of $\mathrm{Au}$ catalysts prepared by sputtering, since technologies for the production of related $\mathrm{Au}$ materials by this technique have been already applied on an industrial scale: for instance, a continuous flow production of Au-recovered glasses. $^{75}$

\section{EXPERIMENTAL SECTION}

4.1. General Considerations. All syntheses were performed using standard Schlenk techniques under an argon atmosphere. Chemicals were purchased from Sigma-Aldrich and purified by standard procedures. ${ }^{76} \mathrm{H}_{2}(>99.999 \%)$ and $\mathrm{D}_{2}$ (D $>99.8 \%$ ) were purchased from White-Martins. Petrobras provided the $\gamma-\mathrm{Al}_{2} \mathrm{O}_{3}$ used in this study. Synthesis and characterization of the IL-hybrid $\gamma-\mathrm{Al}_{2} \mathrm{O}_{3}$ supports ( $\mathrm{B1}$ and B2) are reported elsewhere. ${ }^{48,49}$ Fourier transform infrared (FT-IR) spectra were obtained using a ABB FTLA 2000 instrument with a resolution of $4 \mathrm{~cm}^{-1}$ with 128 cumulative scans. ${ }^{13} \mathrm{C}$ and ${ }^{29} \mathrm{Si}$ solid-state cross-polarization magic angle spinning nuclear magnetic resonance (CP-MAS NMR) spectra were performed using a Bruker $400 \mathrm{MHz}$ spectrometer at the CNANO/UFRGS. $\mathrm{N}_{2}$ isotherms of the catalysts, previously degassed at $100{ }^{\circ} \mathrm{C}$ under vacuum for $3 \mathrm{~h}$, were obtained using Tristar 3020 Micromeritics equipment. Specific surface areas were determined by the Brunauer-Emmett-Teller (BET) multipoint method, and the average pore size was obtained by the Barrett-Joyner-Halenda (BJH) method. Au content was determined by X-ray fluorescence (XRF) carried out using a Shimadzu XRF-1800 sequential X-ray fluorescence spectrometer. Samples were prepared in $\mathrm{KBr}$, and calibration was performed using bromine as an internal standard. Rutherford backscattering spectroscopy (RBS) measurements were carried out in a $3 \mathrm{MV}$ Tandetron accelerator using a $\mathrm{He}^{+}$ion beam of 1.5 $\mathrm{MeV}$ at IF/UFRGS. The Si surface-barrier detector was positioned at a scattering angle of $165^{\circ}$. Scanning electron microscopy with energy-dispersive X-ray spectroscopy (SEMEDS) was performed with an EVO 50 from Zeiss, operated at $10 \mathrm{kV}$. The images were obtained from the scratched area of the samples. Transmission electron microscopy (TEM) was performed on a JEOL-JEM 1200ExII electron microscope operating at $200 \mathrm{kV}$. The samples were prepared by the slow evaporation of a drop of each colloidal solution deposited under an argon atmosphere onto a holey-carbon-covered copper grid. X-ray diffraction (XRD) analyses were carried out using a Philips X'Pert MPD diffractometer with BraggBrentano geometry using a graphite curved crystal with $\mathrm{Cu} \mathrm{K} \alpha$ $\mathrm{X}$-ray radiation (1.5406 ̊).

4.2. X-ray Photoelectron Spectroscopy (XPS). XPS measurements were performed using a Kratos AXIS Ultra DLD instrument. Samples were mounted on the standard Kratos sample bar using double-sided tape (Sellotape brand), inserted into the airlock, and pumped down to $\sim 3 \times 10^{-7}$ Torr overnight before transfer into the instrument analysis chamber. The analysis chamber pressure during the measurements was better than $5 \times 10^{-9}$ Torr. Wide energy range survey scans were collected at a pass energy of $80 \mathrm{eV}$ in hybrid slot lens mode and a step size of $0.5 \mathrm{eV}$. High-resolution data on the $\mathrm{Au}$ $4 \mathrm{f}, \mathrm{Au} \mathrm{VB}, \mathrm{Al} 2 \mathrm{p}, \mathrm{Cl} 2 \mathrm{p}, \mathrm{F} 1 \mathrm{~s}, \mathrm{O} 1 \mathrm{~s}, \mathrm{~N} 1 \mathrm{~s}$, and $\mathrm{C} 1 \mathrm{~s}$ photoelectron peaks were collected at a pass energy of $20 \mathrm{eV}$ over energy ranges suitable for each peak and collection times of $5 \mathrm{~min}$, with step sizes of $0.1 \mathrm{eV}$. The charge neutralizer filament was used to prevent the sample charging over the irradiated area. The X-ray source was a monochromated $\mathrm{Al} \mathrm{K} \alpha$ emission, run at $10 \mathrm{~mA}$ and $12 \mathrm{kV}(120 \mathrm{~W})$. The data were captured using Kratos VISIONII software and exported into vms format for data processing with CASAXPS (version 2.3.17). The high-resolution spectra were analyzed using a Lorentzian asymmetric line shape convoluted with a Gaussian function for each chemical component. The high-resolution data were charge corrected to the reference peak of $\mathrm{Al} 2 \mathrm{p}$ signal of $\mathrm{Al}_{2} \mathrm{O}_{3}$ at $74.5 \mathrm{eV}$. 49 The energy range for each "pass energy"

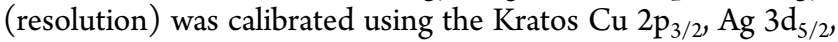
and $\mathrm{Au} 4 \mathrm{f}_{7 / 2}$ three-point calibration method. The transmission function was calibrated using a clean gold sample method for all lens modes and the Kratos transmission generator software within Vision II.

4.3. Preparation of AuNPs. As a general procedure for the AuNP preparation by sputtering deposition, $1.0 \mathrm{~g}$ of each support $\left(\gamma-\mathrm{Al}_{2} \mathrm{O}_{3}, \mathbf{B 1}\right.$, and $\left.\mathbf{B 2}\right)$ was placed in a conical aluminum flask and inside a vacuum chamber containing an electromagnetic oscillator with variable controlled frequency, 
which allows for constant movement of the conical flask. Then, the chamber was closed and its pressure lowered to a base pressure of $4 \mu \mathrm{bar}$, with the supports being evacuated at this pressure for $4 \mathrm{~h}$. Then, the vacuum chamber was placed under a sputtering working pressure of $4 \mathrm{mbar}$ by adding an argon flow. The supports were continuously homogenized by revolving the aluminum flask at a vibration frequency of $24 \mathrm{~Hz}$. The Au was sputtered onto the revolving support at $35 \mathrm{~mA}$ of discharge current during 4.5 min to give the $\mathrm{Au} / \mathrm{Al}_{2} \mathrm{O}_{3}, \mathrm{Au} / \mathrm{B1}$, and $\mathrm{Au} /$ B2 catalysts. After the deposition, the chamber was vented with nitrogen and the red powders were recovered and stored under an argon atmosphere for further characterization and application.

4.4. Hydrogenation Reactions. As a general procedure for the hydrogenation reactions, the catalyst $(0.5 \mu \mathrm{mol}$ of $\mathrm{Au})$, substrate (substrate $/ \mathrm{Au}=250)$, and solvent $(5 \mathrm{~mL})$ were placed in a $50 \mathrm{~mL}$ reactor (Parr Multireactor 4590). The reaction vessel was pressurized under 25 bar of $\mathrm{H}_{2}$ and warmed to $100{ }^{\circ} \mathrm{C}$. Aliquots were regularly taken during the reaction. After the reaction time, the reactor was cooled to room temperature and then depressurized. The conversion and selectivity were determined by GC analysis of the reaction samples.

4.5. Identification and Quantification of the Hydrogenation Reactions. GC analyses were run with an Agilent Technologies GC System 6820: injector and detector (FID) temperature of $260{ }^{\circ} \mathrm{C} ; \mathrm{N}_{2}$ as the carrier $\left(1 \mathrm{~mL} \mathrm{~min}^{-1}\right)$; column head pressure of $10 \mathrm{psi}$; temperature program from $40{ }^{\circ} \mathrm{C}(10$ min) to $250{ }^{\circ} \mathrm{C}$ at a heating rate of $10{ }^{\circ} \mathrm{C} \mathrm{min}{ }^{-1}$; DB- 17 column $(30 \mathrm{~m} \times 0.25 \mathrm{~mm} \times 0.25 \mu \mathrm{m})$ for the hydrogenation of 1,3-cyclohexadiene (1), 1,3-cyclooctadiene (5), styrene (24), crotonaldehyde (29), cinnamaldehyde (32), 2-cyclohexenone (34) and 2-methyl-2-cyclohexenone (39); alumina column (30 $\mathrm{m} \times 0.43 \mathrm{~mm}$ ) for the hydrogenation of 1,3-butadiene (8), 2 methyl-1,3-butadiene (13), 2,3-dimethyl-1,3-butadiene (17), and 2-pentyne (26); HP-5 column $(30 \mathrm{~m} \times 0.20 \mathrm{~mm} \times 0.30$ $\mu \mathrm{m})$ for the hydrogenation of $\alpha$-terpinene (20). ${ }^{1} \mathrm{H}$ and ${ }^{2} \mathrm{H}$ NMR analyses of the samples obtained by $\mathrm{D}_{2}$ reduction of 1,3cyclohexadiene (1) catalyzed by AuNPs were performed using a Varian $400 \mathrm{MHz}$ spectrometer at CNANO/UFRGS. The incorporation of $\mathrm{D}$ in the reaction products was quantified by comparing the ${ }^{1} \mathrm{H}$ NMR spectra with these obtained from a standard sample (relaxation delay 1-10 s) and by performing ${ }^{2} \mathrm{H}$ NMR experiments (relaxation delay $1-10 \mathrm{~s}$ ). ${ }^{45,46,48}$

\section{ASSOCIATED CONTENT}

\section{S Supporting Information}

The Supporting Information is available free of charge on the ACS Publications website at DOI: 10.1021/acscatal.7b00391.

Additional literature data (tables and comments) and further characterization and kinetic data (PDF)

\section{AUTHOR INFORMATION}

Corresponding Author

*E-mail for J.D.: Jairton.Dupont@nottingham.ac.uk.

ORCID

Jairton Dupont: 0000-0003-3237-0770

Notes

The authors declare no competing financial interest.

\section{ACKNOWLEDGMENTS}

We thank the CNPq, CAPES, INCT-Catal., Petrobras, EPSRC: LiPPS XPS system, and EP/K005138/1 "University of Nottingham Equipment Account" for providing financial support for this work.

\section{REFERENCES}

(1) Liu, P.; Zhao, Y.; Qin, R.; Mo, S.; Chen, G.; Gu, L.; Chevrier, D. M.; Zhang, P.; Guo, Q.; Zang, D.; Wu, B.; Fu, G.; Zheng, N. Science 2016, 352, 797-800

(2) Bai, L.; Wang, X.; Chen, Q.; Ye, Y.; Zheng, H.; Guo, J.; Yin, Y.; Gao, C. Angew. Chem., Int. Ed. 2016, 55, 15656-15661.

(3) Zhang, P.; Qiao, Z.-A.; Jiang, X.; Veith, G. M.; Dai, S. Nano Lett. 2015, 15, 823-828.

(4) Pan, M.; Brush, A. J.; Pozun, Z. D.; Ham, H. C.; Yu, W.-Y.; Henkelman, G.; Hwang, G. S.; Mullins, C. B. Chem. Soc. Rev. 2013, 42, $5002-5013$

(5) Mitsudome, T.; Kaneda, K. Green Chem. 2013, 15, 2636-2654.

(6) Cárdenas-Lizana, F.; Keane, M. A. J. Mater. Sci. 2013, 48, 543564.

(7) Buchanan, D. A.; Webb, G. J. Chem. Soc., Faraday Trans. 1 1975, $71,134-144$.

(8) Bond, G. C.; Sermon, P. A.; Webb, G.; Buchanan, D. A.; Wells, P. B. J. Chem. Soc., Chem. Commun. 1973, 444b-445.

(9) Erkelens, J.; Kemball, C.; Galwey, A. K. Trans. Faraday Soc. 1963, 59, 1181-1191.

(10) Sachtler, W. M. H.; Boer, N. H. d. J. Phys. Chem. 1960, 64, $1579-1580$.

(11) Tang, H.; Wei, J.; Liu, F.; Qiao, B.; Pan, X.; Li, L.; Liu, J.; Wang, J.; Zhang, T. J. Am. Chem. Soc. 2016, 138, 56-59.

(12) Vile, G.; Perez-Ramirez, J. Nanoscale 2014, 6, 13476-13482.

(13) Si, R.; Tao, J.; Evans, J.; Park, J. B.; Barrio, L.; Hanson, J. C.; Zhu, Y.; Hrbek, J.; Rodriguez, J. A. J. Phys. Chem. C 2012, 116, 2354723555.

(14) Sun, K.-Q.; Hong, Y.-C.; Zhang, G.-R.; Xu, B.-Q. ACS Catal. 2011, 1, 1336-1346.

(15) Shang, L.; Liang, Y.; Li, M.; Waterhouse, G. I. N.; Tang, P.; Ma, D.; Wu, L.-Z.; Tung, C.-H.; Zhang, T. Adv. Funct. Mater. 2017, 27, 1606215 .

(16) Zopes, D.; Stein, B.; Mathur, S.; Graf, C. Langmuir 2013, 29, 11217-11226.

(17) Comotti, M.; Della Pina, C.; Matarrese, R.; Rossi, M. Angew. Chem., Int. Ed. 2004, 43, 5812-5815.

(18) Keim, W. Angew. Chem., Int. Ed. Engl. 1990, 29, 235-244.

(19) Taylor, H. S. J. Phys. Chem. 1925, 30, 145-171.

(20) Kubas, G. J. Chem. Rev. 2007, 107, 4152-4205.

(21) Voges, M. H.; Bullock, R. M. J. Chem. Soc., Dalton Trans. 2002, $759-770$.

(22) Magee, M. P.; Norton, J. R. J. Am. Chem. Soc. 2001, 123, 17781779.

(23) Bullock, R. M.; Voges, M. H. J. Am. Chem. Soc. 2000, 122, 12594-12595.

(24) Bullock, R. M.; Song, J.-S.; Szalda, D. J. Organometallics 1996, $15,2504-2516$

(25) Bullock, R. M.; Rappoli, B. J. J. Chem. Soc., Chem. Commun. 1989, 1447-1448.

(26) García-Melchor, M.; López, N. J. Phys. Chem. C 2014, 118, 10921-10926.

(27) Hartfelder, U.; Kartusch, C.; Makosch, M.; Rovezzi, M.; Sa, J.; van Bokhoven, J. A. Catal. Sci. Technol. 2013, 3, 454-461.

(28) Joubert, J.; Salameh, A.; Krakoviack, V.; Delbecq, F.; Sautet, P.; Copéret, C.; Basset, J. M. J. Phys. Chem. B 2006, 110, 23944-23950.

(29) Cano, I.; Huertos, M. A.; Chapman, A. M.; Buntkowsky, G.; Gutmann, T.; Groszewicz, P. B.; van Leeuwen, P. W. N. M. J. Am. Chem. Soc. 2015, 137, 7718-7727.

(30) Cano, I.; Chapman, A. M.; Urakawa, A.; van Leeuwen, P. W. N. M. J. Am. Chem. Soc. 2014, 136, 2520-2528. 
(31) Ren, D.; He, L.; Yu, L.; Ding, R.-S.; Liu, Y.-M.; Cao, Y.; He, H.Y.; Fan, K.-N. J. Am. Chem. Soc. 2012, 134, 17592-17598.

(32) He, L.; Wang, L.-C.; Sun, H.; Ni, J.; Cao, Y.; He, H.-Y.; Fan, K.N. Angew. Chem., Int. Ed. 2009, 48, 9538-9541.

(33) Boronat, M.; Concepción, P.; Corma, A. J. Phys. Chem. C 2009, 113, 16772-16784.

(34) Boronat, M.; Illas, F.; Corma, A. J. Phys. Chem. A 2009, 113, 3750-3757.

(35) Serna, P.; Concepción, P.; Corma, A. J. Catal. 2009, 265, 19-25.

(36) Corma, A.; Boronat, M.; Gonzalez, S.; Illas, F. Chem. Commun. 2007, 3371-3373.

(37) Zhang, X.; Llabrés i Xamena, F. X.; Corma, A. J. Catal. 2009, $265,155-160$.

(38) Zhang, X.; Shi, H.; Xu, B.-Q. Catal. Today 2007, 122, 330-337. (39) Liu, Z.-P.; Wang, C.-M.; Fan, K.-N. Angew. Chem., Int. Ed. 2006, $45,6865-6868$.

(40) Zhang, X.; Shi, H.; Xu, B.-Q. Angew. Chem., Int. Ed. 2005, 44, $7132-7135$.

(41) Filonenko, G. A.; Vrijburg, W. L.; Hensen, E. J. M.; Pidko, E. A. J. Catal. 2016, 343, 97-105.

(42) Guan, Y.; Hensen, E. J. M. Phys. Chem. Chem. Phys. 2009, 11, 9578-9582.

(43) Escalle, A.; Mora, G.; Gagosz, F.; Mézailles, N.; Le Goff, X. F.; Jean, Y.; Le Floch, P. Inorg. Chem. 2009, 48, 8415-8422.

(44) Ito, H.; Saito, T.; Miyahara, T.; Zhong, C.; Sawamura, M. Organometallics 2009, 28, 4829-4840.

(45) Luza, L.; Rambor, C. P.; Gual, A.; Bernardi, F.; Domingos, J. B.; Grehl, T.; Brüner, P.; Dupont, J. ACS Catal. 2016, 6, 6478-6486.

(46) Luza, L.; Gual, A.; Rambor, C. P.; Eberhardt, D.; Teixeira, S. R.; Bernardi, F.; Baptista, D. L.; Dupont, J. Phys. Chem. Chem. Phys. 2014, 16, 18088-18091.

(47) Luza, L.; Gual, A.; Dupont, J. Chem CatChem 2014, 6, 702-710. (48) Luza, L.; Gual, A.; Eberhardt, D.; Teixeira, S. R.; Chiaro, S. S. X.; Dupont, J. Chem CatChem 2013, 5, 2471-2478.

(49) Foppa, L.; Luza, L.; Gual, A.; Weibel, D. E.; Eberhardt, D.; Teixeira, S. R.; Dupont, J. Dalton Trans. 2015, 44, 2827-2834.

(50) Ali, M.; Abarca, G.; Eberhardt, D.; Gual, A.; Bernardi, F.; Teixeira, S. R.; Dupont, J. Tetrahedron 2016, DOI: 10.1016/ j.tet.2016.11.043.

(51) Luska, K. L.; Bordet, A.; Tricard, S.; Sinev, I.; Grünert, W.; Chaudret, B.; Leitner, W. ACS Catal. 2016, 6, 3719-3726.

(52) Luska, K. L.; Julis, J.; Stavitski, E.; Zakharov, D. N.; Adams, A.; Leitner, W. Chem. Sci. 2014, 5, 4895-4905.

(53) Uematsu, T.; Baba, M.; Oshima, Y.; Tsuda, T.; Torimoto, T.; Kuwabata, S. J. Am. Chem. Soc. 2014, 136, 13789-13797.

(54) Wender, H.; de Oliveira, L. F.; Migowski, P.; Feil, A. F.; Lissner, E.; Prechtl, M. H. G.; Teixeira, S. R.; Dupont, J. J. Phys. Chem. C 2010, 114, 11764-11768.

(55) Torimoto, T.; Okazaki, K.-i.; Kiyama, T.; Hirahara, K.; Tanaka, N.; Kuwabata, S. Appl. Phys. Lett. 2006, 89, 243117.

(56) Tanaka, T.; Ohyama, J.; Teramura, K.; Hitomi, Y. Catal. Today 2012, 183, 108-118.

(57) Suzuki, S.; Ohta, Y.; Kurimoto, T.; Kuwabata, S.; Torimoto, T. Phys. Chem. Chem. Phys. 2011, 13, 13585-13593.

(58) Büttner, M.; Kröger, H.; Gerhards, I.; Mathys, D.; Oelhafen, P. Thin Solid Films 2006, 495, 180-185.

(59) Boyen, H. G.; Kästle, G.; Weigl, F.; Ziemann, P.; Schmid, G.; Garnier, M. G.; Oelhafen, P. Phys. Rev. Lett. 2001, 87, 276401.

(60) Sobota, M.; Happel, M.; Amende, M.; Paape, N.; Wasserscheid, P.; Laurin, M.; Libuda, J. Adv. Mater. 2011, 23, 2617-2621.

(61) Sievers, C.; Jimenez, O.; Müller, T. E.; Steuernagel, S.; Lercher, J. A. J. Am. Chem. Soc. 2006, 128, 13990-13991.

(62) Torimoto, T.; Tsuda, T.; Okazaki, K.-i.; Kuwabata, S. Adv. Mater. 2010, 22, 1196-1221.

(63) Arras, J.; Steffan, M.; Shayeghi, Y.; Ruppert, D.; Claus, P. Green Chem. 2009, 11, 716-723.

(64) Kernchen, U.; Etzold, B.; Korth, W.; Jess, A. Chem. Eng. Technol. 2007, 30, 985-994.
(65) Steinrück, H. P.; Libuda, J.; Wasserscheid, P.; Cremer, T.; Kolbeck, C.; Laurin, M.; Maier, F.; Sobota, M.; Schulz, P. S.; Stark, M. Adv. Mater. 2011, 23, 2571-2587.

(66) Caporali, S.; Bardi, U.; Lavacchi, A. J. Electron Spectrosc. Relat. Phenom. 2006, 151, 4-8.

(67) Stassen, H. K.; Ludwig, R.; Wulf, A.; Dupont, J. Chem. - Eur. J. 2015, 21, 8324-8335.

(68) Fountoulaki, S.; Daikopoulou, V.; Gkizis, P. L.; Tamiolakis, I.; Armatas, G. S.; Lykakis, I. N. ACS Catal. 2014, 4, 3504-3511.

(69) Abad, A.; Corma, A.; García, H. Chem. - Eur. J. 2008, 14, 212222.

(70) Umpierre, A. P.; de Jesús, E.; Dupont, J. ChemCatChem 2011, 3, $1413-1418$.

(71) Mattson, B.; Foster, W.; Greimann, J.; Hoette, T.; Le, N.; Mirich, A.; Wankum, S.; Cabri, A.; Reichenbacher, C.; Schwanke, E. J. Chem. Educ. 2013, 90, 613-619.

(72) Bus, E.; Miller, J. T.; van Bokhoven, J. A. J. Phys. Chem. B 2005, 109, 14581-14587.

(73) Cortright, R. D.; Dumesic, J. A. Adv. Catal. 2001, 46, 161-264.

(74) Murzin, D. Y. Chem. Eng. Sci. 2009, 64, 1046-1052.

(75) SunGuard Advanced Architectural Glass - Sputter Coating, https:// www.guardianglas s.com/commercial/ AboutGuardian Sun Guard / About Sun GuardGlass / PostTemperableSputterCoatingTechnology/index.htm, accessed December 20, 2016.

(76) Armarego, W. L. F.; Perrin, D. D. Purification of Laboratory Chemicals; Butterworth-Heineman: London, 1997. 